Article

\title{
A Systematic Review and Conceptual Model of International Student Mobility Decision-Making
}

\author{
Anouk J. Albien ${ }^{1,2 *}$ and Ngoako J. Mashatola ${ }^{1}$ \\ ${ }^{1}$ Department of Curriculum Studies, Centre for Higher and Adult Education, Stellenbosch University, 7600 Stellenbosch, \\ South Africa; E-Mails: anouka@sun.ac.za (A.J.A.), japhta.mash@gmail.com (N.J.M.) \\ ${ }^{2}$ Work \& Organisational Psychology Division, Psychology Institute, University of Bern, 3012 Bern, Switzerland \\ * Corresponding author
}

Submitted: 23 October 2020 | Accepted: 14 January 2021 | Published: 25 March 2021

\begin{abstract}
This research synthesizes the most recent studies on the international student mobility of higher education students. Our aim is to begin to conceptualise and predict the barriers, enablers and determinants from an organisational psychology perspective that may contribute to the limited decision-making of higher education students to become internationally mobile. Previous studies were used to examine the uncertainties and difficulties documented in other international student groups to try to understand the determinants of internationally mobile versus non-internationally mobile students, and make transferrable conceptual links to South African higher education students. These conceptual links are framed in an organizational psychology perspective. This article uses a systematic review methodology and began by framing review objectives, identifying relevant publications, establishing criteria for selecting the studies that were analyzed, summarizing the evidence found, and drawing relevant conclusions. A conceptual model is proposed as an extension of the current international student mobility literature and merged with organizational psychology theory to develop a new future research line. Research limitations are addressed, and practical implications are discussed to assess whether interventions can be created to support international mobility decision-making amongst international students in general, and South African higher education students in particular, to create a globally competitive workforce and sustainable employment paths.
\end{abstract}

\section{Keywords}

global workforce; higher education students; international student mobility; internationally non-mobile students; mobility barriers; mobility decision-making; mobility determinants; mobility enablers; organizational psychology; South Africa; sustainable employment

\section{Issue}

This article is part of the issue "Decision-Making under Uncertainty: African Migrants in the Spotlight" edited by Didier Ruedin (University of the Witwatersrand, South Africa / University of Neuchâtel, Switzerland).

(C) 2021 by the authors; licensee Cogitatio (Lisbon, Portugal). This article is licensed under a Creative Commons Attribution 4.0 International License (CC BY).

\section{Introduction}

International student mobility is one of the career transitions fraught with uncertainties. International student mobility here is defined as students who follow a time-based cross-border movement, this includes all types of international student mobility, driven by the underlying intention of gaining better education or professional opportunities in the face of unstable world-of-work opportunities (Cao, Hirschi, \& Deller,
2012). Career-related migration has gained increasing popularity as an avenue to gain access to world-of-work opportunities that may not have been accessible in an individual's host country (Ravasi, Salamin, \& Davoine, 2015). International student mobility has been linked to increases of transferrable skills that would facilitate graduates' employability in a world-wide market (Souto-Otero, Huisman, De Beerkens, Wit, \& Vujic, 2013). International student mobility has taken precedence to develop a future workforce that aims to increase the 
level of acquired skills, allow students to be able to compete in the global marketplace, enhance the interaction between citizens of different countries, and stimulate labor markets (Institute of International Education, 2011). Therefore, the present study aims to examine the decision-making processes of higher education students' migrant aspirations or migration motivations, which answers the call for research that aims to enhance student employability in a local and global world-of-work from an organizational psychology perspective.

\subsection{Recent Statistics Regarding Mobility of South African Students}

Specifically, South African youth (aged 15 to 34) are vulnerable in the labor market, with an unemployment rate of $63.4 \%$ (Statistics South Africa, 2019). Amongst graduates in this age group, the unemployment rate was $31 \%$, which shows that education increases young people's prospects in the South African labor market. Approximately $56.4 \%$ of the 10.3 million South African youth (aged 15 to 24 years) are reported not to be in employment, education, or training (Statistics South Africa, 2019). In addition, a rural-urban divide results in limited educational and career development opportunities for the youth, which are perpetuated by the poor quality of schools in South Africa's historically disadvantaged areas (i.e., Townships; see Blustein, Franklin, Makiwane, \& Gutowski, 2017). Due to these contextual realities and disparities, higher education in South Africa has not reached its full potential or capacity to level out residual post-apartheid inequalities (Potgieter, Harding, Kritzinger, Somo, \& Engelbrecht, 2015).

International student mobility programs have been established to facilitate access to international university education opportunities to equip students with transferrable skills and tools that help to navigate a globally competitive job market (Efiritha, Nogget, \& Nyevero, 2012). However, it is unclear what factors are underlying South African students' hesitance in becoming internationally mobile. Previous research has found that if children have parents who were born outside of their home country (i.e., outside of South Africa), then these children would be more likely to anticipate in international mobility (O'Flaherty, Skrbis, \& Tranter, 2007). A similar phenomenon occurs when the individual was born overseas, then he/she will anticipate moving to another country in the future, in comparison to individuals who are born in a country and raised by citizens of that country. Additionally, there is a rural-urban divide, where many South African students need to be mobile within South Africa for educational and work opportunities, and so it may be that these individuals only move as far as is necessary to achieve a certain objective, and that these movements are not anticipated to be international (Skrbis, Woodward, \& Bean, 2014).

Migration in South Africa is a multi-layered and a contentious point, with anti-foreigner attitudes and a flux of migrants and students from other African countries entering South Africa. According to Afrobarometer research (Mataure, 2013) the outgoing movements range between 1 to $5 \%$, which are far less than the $28 \%$ who aspire to leave South Africa (but never do), and the $67 \%$ of South African youth wanting to stay in South Africa. In addition, only specific destinations are taken into consideration, these are the UK, Australia, and North America, rarely are other international countries considered. Nonetheless, what the underlying reasons or what the decision-making processes may be for these choices remains unclear. In a South African context specifically international student mobility is under-researched, but there is a growing concern of higher education institutions that South African university students are not applying for existing exchange programs.

\section{Methods}

Seeking to contribute to the literature gap on international student mobility, this study analyzes South African University Students' determinants of international mobility aspirations or motivators through a systematic review of the recent corpus of literature on the topic using an organizational psychology lens. The main overarching research purpose of our study is to contribute to the sustainable employment and transferable skill development of higher education students. We achieve this by identifying the motivators, barriers, and enablers to international mobility, and give suggestions for the development of interventions that should facilitate mobility decision-making. Our two more direct objectives are the following: (1) To examine the uncertainties or difficulties documented in international student groups to understand the decision-making processes and determinants of internationally mobile versus non-internationally mobile students; and (2) to make transferrable conceptual links to South African higher education students that extend beyond socioeconomic conditions and other relevant determinants to present a conceptual model that can be used. In a follow-up study we will also intend to empirically test the conceptual model developed in the present article, thus directly contributing to the field of international student mobility. Therefore, we offer some new perspectives for higher education institutions and other role players interested in improving their position in the international education market by understanding the determinants of international student mobility aspirations.

\subsection{Search Strategy}

Although international student mobility has been extensively researched, we were interested in examining this phenomenon from an organizational psychology perspective and this interdisciplinary approach is notably absent in the literature base. In addition, research on South African university students and international 
mobility is limited. As a result, we used a two-step process to try and gain as many relevant literature matches as possible. In the first step, we used the following combination of keywords to explore the research topic: "international student mobility" and/or "enablers" and/or "barriers" and/or "determinants." These keywords were selected based on the number of hits that resulted in their combined usage and based on terms often used in an organizational psychology context. Then, as the second step, we added (and/or) "South African students" to the search string to assess what South African studies had been published or were in press. Due to the large number of studies that emerged, we screened the studies to be included in the present study using our research objectives from an organizational psychology perspective.

\subsection{Selection Criteria}

We limited our search to peer-reviewed journals that were readily accessible, published between 2010 and 2020 in English. In a South African context, the language of education and commerce remains English, so we were not concerned about our language choice being an exclusionary factor. In our sifting process we identified the most influential and so-called classic papers, indicated by a high number of citations within the last 10 years to attain an overview of research published on this research topic. We focused only on higher education student samples and international student mobility and excluded any other population groups. In the first step of our research process, we searched databases that were internationally renowned as high quality, such as Scopus, ScienceDirect and Taylor \& Francis. We included content that was general to international student mobility that discussed worldwide challenges, enablers and determinants of higher education students in undertaking international mobility experiences. In the second step of our search process, we also included databases that would allow access to South African research studies such as Sabinet, Google Scholar, and Academia. We also included content that discussed South African students and their higher education trajectories and any mobility experiences (i.e., rural to urban, other local South African movements and international mobility) mentioned to gain as much perspective into the phenomena in question. Papers were excluded in the two-step process that focused on: acculturation; psychological adjustment; identity development processes linked to international mobility experiences; and subjective experiences of students who had migrated. Exclusions were also made on a case-by-case basis if the research papers were too focused on specific population groups or countries and if we believed that these findings could not be transferred to other contexts (i.e., other international student mobility groups or the South African context).

\subsection{Assessment Procedure}

Our first step was applied in the ScienceDirect database, where we initially identified 931 research papers based on the number of hits that combined usage of our main search keywords in titles, abstracts and/or keywords. Of these, 485 papers were excluded because they were published before 2010. Another 471 papers were excluded because the abstract revealed that they did not focus on our selection criteria. The full texts of the remaining 14 papers were then reviewed and 12 papers were excluded because they examined variables that were not directly linked to international student mobility barriers and determinants. As a result, we included two papers on international student mobility in the current review from ScienceDirect.

The same process was applied to the Taylor \& Francis database, where we identified 10,052 papers, 5103 of which were excluded because they were published before 2010; 4869 papers were excluded because the abstract revealed that they did not focus on international student mobility barriers or determinants. The full texts of the remaining 80 papers were then reviewed and 78 papers were excluded because they examined variables that were not directly linked to our selection criteria. As a result, two papers from Taylor \& Francis were selected.

In the Scopus database we identified 1309 papers with the combined usage of our main search keywords in titles, abstracts and/or keywords. Of these, 828 papers were excluded because they were published before 2010; another 440 were excluded because the abstract revealed that they did not focus on international student mobility barriers or determinants. The full texts of the remaining 41 papers were then reviewed and papers were excluded because they examined variables that were not directly linked to ISM barriers and determinants. As a result, two papers from Scopus were selected.

The second step of our procedure was applied to the Sabinet database to identify South African published papers. Initially we had 1345 hits in titles, abstracts and/or keywords; 683 papers were excluded because they were published before 2010 and 653 were excluded because the abstract revealed that they did not focus on international student mobility barriers, determinants or South African students. The full texts of the remaining nine papers were then reviewed and seven of these were excluded because they examined variables that were not directly linked to international student mobility barriers and determinants. As a result, we selected two papers from Sabinet.

The same process was applied to the Academia database, where we identified 10,895 hits in titles, abstracts and/or keywords; 683 of these papers were then excluded because they were published before 2010 and 653 were excluded because the abstract revealed that they did not focus on international student mobility barriers, determinants or South African students. The full texts of the remaining nine papers were then reviewed, 
seven papers were excluded because they examined variables that were not directly linked to international student mobility barriers and determinants. As a result, we selected two papers from Academia.

Finally, the second step of our procedure was also applied in the Google Scholar database, resulting in 10,400 hits in titles, abstracts and/or keywords. Of these, 1470 papers were excluded because they were published before 2010 and 7928 were excluded because the abstract revealed that they did not focus on international student mobility barriers, determinants or South African students. The remaining 1002 papers were then reviewed and only 130 were easily accessible. 125 papers were excluded because they examined variables that were not directly linked to international student mobility barriers and determinants, and an additional three papers were excluded due to repetition. As a result, we included two papers from Google Scholar is our study. In total, we included 12 articles in this review.

\section{Findings}

In the 12 articles that we selected to review (see the Supplementary File for details) there were dominant themes that emerged. In the section below we will provide an overview of the international student mobility research studies conducted in the last 10 years from an organizational perspective. Thereafter, these findings will be applied to a South African context due to the lack of studies documented in a Global South context. Lastly, a theoretical integration and a conceptual model is presented that could be used to predict future mobility motivations and aspirations in university students in general, and South African students in particular.

\subsection{Description of Mobility Movements}

Mobility movements in the articles reviewed were discussed from different perspectives. The first perspective is that of occupational mobility (Yakhina, Yakovlev, Kozhevnikova, Nuretdinova, \& Solovyeva, 2016), and the second perspective is based on mobility movements centring around a global demand for education (Prazeres, 2013). Finally, mobility movements were discussed according to key demographic variables that Skrbis et al. (2014) have examined.

The first perspective is that of graduate students needing to become occupationally mobile, which is tied to social, labor and occupational mobility as presented by Yakhina et al. (2016). The underlying motivations for an individual to undertake these types of mobility are inequality, power, education or prestige. Social mobility is usually described as a change in the individual's status (vertical mobility), a change in location without a change of status (horizontal mobility) or, in some cases, a combination of both. Labor mobility, on the other hand, is the transition of place of employment, changes in the sector of employment or the nature of the work. Most importantly, occupational mobility refers to the qualities of the person, activities, and processes undertaken to reach self-actualisation in occupation and life environments (Yakhina et al., 2016). This concept can be easily tied to the concept of a boundaryless career orientation, which is used in organizational psychology to facilitate successful worldwide movements in social, economic, cultural, and political interactions.

Another perspective focused on mobility movements cantering around a global demand for education, where students worldwide were attracted to prestigious educational programmes in the Global North. Noticeably, there seems to be a lack of research on movements to and from the Global South, and the recommendation was made for future research to explore international student mobility to and from developing world countries. According to Prazeres (2013), the movement of students from developing work countries to higher education institutions in developed countries was described as "vertical mobility" to indicate economic advancement. In comparison, "horizontal mobility" was used to describe the movement between higher education institutions of more or less the same economic advancement and academic quality. The key findings were that students were attracted to higher education institutions with high programme quality and who could afford the costs linked to mobility movements, which were either short-term, linked to a degree or transnational (i.e., completing higher education in the home country but enrolled in a foreign university programme). A global demand for education often translates into the demand for an English-speaking and AngloSaxon higher education, thus making English-speaking countries a popular destination for students (i.e., USA, UK, Australia, Canada, and New Zealand), but Germany and France were also popular destinations. Regardless of the destination, mobile students had better job and economic opportunities than those who were not mobile, so mobility increased their cultural capital. In comparison, students who stayed in their origin country had more familial ties, viewed higher education institutions at home as reputable and lacked a "mobility culture."

The last perspective on mobility movements was tied to three key structural variables in an Australian context as presented by Skrbis et al. (2014). Patterns of mobility aspirations were seen to vary based on gender, school sector, and geographical location variables. Girls were observed to have a more positive mobility outlook than boys, and championed future mobility across all variables. In terms of the school sector, students from independent schools were more likely to report considering future mobility internationally than those from inter-state schools, which reflects differing socioeconomic statuses and financial resources that influence mobility decision-making. However, geographical location seemed to have a limiting effect, where students who resided in remote areas had increased ambitions to move within their state, but they had dampened ambitions to move internationally. Therefore, socioeconomic 
variables were seen to limit mobility decision-making processes even if these factors were not found to significantly predict mobility aspirations. However, the financial costs limited international movements directly by denying access to prestigious scholarships or indirectly by impeding the development of a boundaryless mindset.

\subsection{Determinants of International Mobility}

In the reviewed articles, there were four main determinants mentioned in the decision-making processes of students who aimed to become internationally mobile. The first determinant was the cost of the higher education programmes students were applying for (Verbik \& Lasanowski, 2007), the second determinant was the financial and living costs present in the host country in comparison to the future potential income that could be generated by taking up this international mobility opportunity (Beine, Noël, \& Ragot, 2013). Thirdly, sociopolitical ties and trade flows between a student's home and host country acted as the third determinant (Hou \& Du, 2020). The fourth determinant was described by Gesing and Glass (2018) as the student-driven demand for quality higher education, which often outpaced the higher education demand.

The first determinant, according to Verbik and Lasanowski (2007), was the cost of higher education. This factor was amongst the top factors influencing the decision to study in a country. For example, for Chinese students who are traditionally New Zealand's largest overseas student population, the key motivational factor was the comparably low cost of an overseas education in New Zealand. In addition, countries such as Japan and Canada had affordable provisions, as well as emerging destinations such as Malaysia, Singapore, and China, with their affordable but prestigious educational courses and low living costs, which made these destinations attractive.

The second determinant of international mobility was costs-benefits calculations that students made of comparing the living costs of the host country versus the future income potential of becoming internationally mobile as described by Beine et al. (2013). The determinants of international student mobility were examined and financial and living costs were identified to increasingly be likely to motivate students to apply to particular destinations, and to deter them from applying to others. The high value of certain currencies could arguably dissuade students from going to high-cost nations, since unfavourable exchange rates exacerbate the financial strain of foreign students, especially those from Africa and Southeast Asia. In this article, students from Africa only represented $11,6 \%$ of international student mobility, in comparison to the strong mobility presence of European students. The motivators of mobility are based on securing a higher income and/or to move to a new country which presents more favourable employment opportunities in the long-term than the student's home country. International student mobility returns are based on the higher education value in terms of the average level of education in their home country or can lead to movement to a third country to seek better education or employment opportunities.

The third determinant of international mobility were socio-political ties and trade flows, although these forces operate on a macro-level, students used these fluctuating factors in their decision-making processes to select the host country. In Hou and Du (2020), an analysis is presented of the international student mobility flow to different countries. Confirmed movements that were observed were that Western developed countries were destinations and developing countries were mainly source countries, showing a clear 'East to West, South to North' movement (Hou \& Du, 2020, p. 10). However, international student mobility patterns fluctuated due to economic and higher education development in emerging countries, as well as changing political and economic connections between countries. Factors that are involved are geographical distances, trade relations, political connections, language differences, historical colonial links, levels of economic development and education quality. Therefore, mobility as a rational individual choice or a family economic decision is made more complex and situated within a temporal socio-political climate of the student's home country as well as that of the host country.

As a result, market forces play a predominant role and reflect inequality and imbalance of higher education development worldwide, where other countries are becoming regional hub countries (i.e., China, Australia, Malaysia, the United Arab Emirates, and Saudi Arabia). South Africa was cited as an emerging strong semiperiphery country strengthening in exchanges and cooperation with core western countries, whilst building regional links to other countries (i.e., South America, Israel, Latvia, and Estonia), as well as being the destination of choice for students from sub-Saharan African countries. Therefore, the economic connections, political relationships, existing historical colonial ties, and linguistic proximity promoted bilateral exchanges.

The fourth determinant of international student mobility was students' demand for quality higher education which was outpacing higher education capacity. Findings presented by Gesing and Glass (2018) indicated that higher education enrolment growth was being driven by students from low- to middle-income countries. This led to the increasing numbers of "glocal" students (i.e., students seeking an international education whilst staying in their home country) who attended higher education institutions at international branch campuses. This new generation of international students were viewed seen as price-sensitive and career-minded, whilst focused on short-term mobility for employment goals. They were first-generation students looking for pathways to work opportunities supported by national immigration policies and were engaging in new forms 
of cross-border, hybrid, and online higher education programs. This fast-growing international student population aimed to ensure that short-term mobility would lead to upward social and economic mobility, regardless of regional conflicts, economic crises, and pandemics.

\subsection{Enablers of International Mobility}

In terms of international mobility enablers, we found two main enablers, the first enabler was the desire to gain an advantage over fellow students and that international mobility could help students achieve this aim to gain employment (Findlay, King, Findlay, Ahrens, \& Dunne, 2012). Secondly, another international mobility enabler is described as intellectual capital, which presupposes an existing network in the host country, high academic qualifications, and language proficiencies, which focuses a certain student demographic (Li, Lo, Lu, Tan, \& Lu, 2020).

The first enabler was the desire of students to gain a competitive edge to facilitate employment, this enabling factor for international mobility was described by Findlay et al. (2012). The search for international student mobility opportunities was based on attending a high status university to gain a form of "distinctiveness" that would be used in an international world-of-work arena to differentiate their employment credentials from peers. International student mobility was based on symbolic capital as 'a distinguishing identity marker' (Findlay et al., 2012, p. 128). Students believed that their international experience could be deployed advantageously in their future career trajectories. Furthermore, international education and the resultant cosmopolitan identities associated with international student mobility would assist building an international career. The possibility of working abroad and developing an internationally mobile career trajectory based on human capital influenced international student mobility decisions.

The second enabler was international mobility driven by gaining intellectual capital, otherwise known as intellectual migration, as proposed by Li et al. (2020). In this study, the decision to undertake international student mobility is influenced more by career aspirations, contextual factors such as (im)migration regulations and the socioeconomic-political conditions of their origin and destination regions. Intellectual migration contends that migratory decisions, trajectories, and trends are tied to gaining intellectual capital. International capital is based on a combination of academic training, (foreign) language proficiency, work experience, knowledge-based translocal and transnational connections (which are personal and professional connections), socio-cultural adaptability, and influential leadership. Intellectual capital was further influenced by the migrants themselves, their social networks, as well as the economy and policies in sending and receiving regions.

Other variables mentioned by Beine et al. (2013) which may act as enablers or barriers to student inter- national mobility were the physical distance from their home country (i.e., negative), a lack of host country language proficiency (i.e., negative), colonial ties (i.e., positive or negative associations), and whether a network is already present in the host country (i.e., positive associations). In addition, Hou and Du (2020) mention that similar cultural background and language were viewed as enabling factors which limited the psychological distance and reduced a sense of strangeness, that could hinder host interaction. These factors are dependent on the student's home country and the trade and historical ties to the host country, which could be dual entities acting as enablers and/or barriers.

\subsection{Barriers to (and Benefits of) International Mobility}

Articles in our review cited many barriers to international mobility, and Souto-Otero et al. (2013) undertook an exploration of the barriers that prevented students from taking part in the Erasmus programme. The main barriers that non-mobile students faced were financial costs ( $61 \%$ compared to $41 \%$ of mobile students), separation from the social support system (i.e., family, partner and friends), which was cited by both non-mobile (47\%) and mobile students ( $23 \%)$, and $43 \%$ of non-mobile students expected their international mobility studies to take longer to complete. Further barriers included struggles in finding accommodation and a lack of understanding of administrative procedures, living conditions, currency exchanges, necessary insurance, and credit transfers. Additional barriers were overseas academic-related teaching methods, academic content, foreign language instruction, limited academic support, and high workload of courses. Non-mobile students preferred to finish their higher education training as soon as possible, to save the costs associated with international student mobility and keep their support systems in place at home. Psychological barriers were also mentioned, such as the fear of new places and creating new social contacts, a lack of self-confidence, and losing connectedness to their home country.

Although international student mobility has many barriers, there are many benefits of mobility. King, Findlay, and Ahrens (2010) examined the relationship between an Erasmus year abroad and subsequent professional life and key benefits of international student mobility. The results show there is a positive impact of international student mobility on employment and the type of work students end up taking. According to King et al. (2010), benefits of mobility include: (1) a high level of satisfaction with current work, (2) a positive impact on income, (3) continuous use of the language of the host country, (4) the ability to use knowledge of the host country professionally, and (5) travel to host country for professional reasons.

Moreover, other findings indicated that reasons for international students to complete programs are to enhance academic credentials, get better paid employ- 
ment opportunities, and provide entry to influential professional networks. This means that there are negative implications when students do not undertake international student mobility opportunities, which can be seen as a potential barrier to students' career development and create unequal employment opportunities.

\section{Applications to a South African Context}

South Africa has been cited as the most unequal country in the world with a Gini coefficient of 65.0 (The World Bank, 2015), with high income inequality, high unemployment, and relatively low growth rates. This inequality is pervasive in the educational system, despite conducive efforts to level post-Apartheid inequalities. The differential pathways of South African students through higher education in the article of Cosser (2018) is presented by tracking a cohort of students from school graduation into and through the South African higher education system. There were vast differences observed in student's performances in school and higher education that are based on socioeconomic status which further impacts the probability of employment and the returns of education of South African workers. The key findings were that persistence and socioeconomic status is a differentiating feature in student progression through, the retention within and completion of higher education programs (Cosser, 2018).

The implications for international student mobility are then painted starkly in terms of socioeconomic status, privileging students from a high socioeconomic background, which could explain the limited number of internationally mobile South African students. However, this does not entirely answer the question of why some South African students who are offered international scholarships often may not accept the opportunity. We would like to argue that there may be some individual differences as stipulated by the boundaryless career theory (Sullivan \& Arthur, 2006), regardless of socioeconomic status, that may make an individual more likely to want to distinguish themselves in an extremely limited and competitive South African job market for university graduates. These individuals can be described as having a boundaryless career orientation and want to ensure they have a skillset that ensures sustainable employability.

Yet, there is an overlooked cultural domain that may hinder South African students from becoming internationally mobile. Collectivistic elements are distributed across South African population groups with some population groups being more or less collectivistic (Albien, 2019). Therefore, differences in career orientations and international student mobility aspirations and motivations may manifest in university students from the Global South countries such as South Africa. As a result, South African students may waver between utilizing international student mobility opportunities needed for their occupational mobility, as well as fulfilling familial obligations, and finding a compromise that may increase their mobility within South Africa but limit their mobility internationally. Therefore, a theoretical framework for international mobility that merges organizational theory with migration theory and takes socioeconomic status into consideration was introduced. We hope that this model proves useful and can be used for different international student population groups from an organizational psychology perspective. This theory will be used as the foundation for the conceptual model that was developed as the second aim of the research article.

\section{Discussion and Theoretical Implications}

Although there are numerous migration theories due to an increasing interest in international migration and mobility, there is a lack of integration between organizational theories of career-related movements and the migration theoretical base. As an overview, migration theories have been described to function at different levels (micro-, meso-, and macro-level), according to discipline (sociological, economic, geographical, etc.), or according to initiation or perpetuation (for a complete review please see Wickramasinghe \& Wimalaratana, 2016). In the present research, an integration of migration system theory, boundaryless career theory and the social cognitive model of career self-management (CSM) will be used as our theoretical foundation.

In migration system theory, the core tenet is that migration contributes to changes on economic, cultural, social, and institutional conditions in the receiving and sending country, with a focus on the macro (economy, political, and cultural systems, etc.) and micro (individual, kinship, and friendship systems) linkages of the places linked to the migration process (Kritz, Lim, \& Zlotnik, 1992). Unlike other migration models, this model emphasizes the link between migration and development (De Haas, 2010), which allows a broader perspective that views development not only as economic in nature but also social. Therefore, it can be argued that migration has the ability to influence the socioeconomic development of the country of origin, encourage subsequent migration at macro- and micro-levels, enhance the individual's human and social capital and improve an individual's employability at a micro-level (university students). In the section below, we aim to present an integrated conceptual framework that links the migration system theory, the boundaryless career theory and the CSM to provide a comprehensive account for international student migration that includes micro- and macrolevels and could be applied to various student population groups but here will be applied to the South African context.

An organizational psychology theory, the boundaryless career theory was integrated to provide an understanding of factors that contributed to career mobility behaviours in individuals and has an established research base that included associations with boundaryless career orientations (Sullivan \& Arthur, 2006). The boundary- 
less career theory explains that a career involves physical and/or psychological mobility and has moved to the forefront of career self-management. Physical mobility is the transition across boundaries (i.e., jobs, firms, occupations, and countries), and psychological mobility is the perception of the career actor of his/her capacity to make transitions (Sullivan \& Arthur, 2006). A boundaryless career can be viewed and operationalized by the degree of mobility exhibited by the career actor along both the physical and psychological mobility continua.

The CSM (Lent \& Brown, 2013) has been applied in various research studies to career exploration and decision-making outcomes in higher education students. Currently scant research exists that examines higher education students in a South African context. It has been predicted that self-efficacy and positive outcome expectations promote goals to engage in exploration/decisional actions and ultimately the followthrough of career exploration into career decisional outcome behaviours (Lent, Ezeofor, Morrison, Penn, \& Ireland, 2016; see Figure 1).

However, the alignment of variables with the CSM model that facilitates the movement from goals to decisional goals, actions, and, ultimately, behavioural outcomes, is still under-researched (Ireland \& Lent, 2018). An extension can be provided of the CSM research base by examining the link between exploratory goals and behaviour, which has been called for in previous research.

\subsection{Proposed Conceptual Model}

In the current study, behavioural outcomes were theorized to be measured by the international student mobility experiences undertaken. This creates a clear follow-through pathway where students can self-report if they have been mobile or non-mobile. The importance of this documentation answers the call to facilitate the movement from goals (understood here as mobility aspirations) to decisional goals (understood here as mobility motivations) that result in actions and, ultimately, behavioural outcomes of being internationally mobile (Ireland \& Lent, 2018). This model allows the decision-making process and determinants involved in international mobility to be explored. Also, the need for self-directed career management competencies (SDCM) based on the CSM model became a research strand that aimed at developing competencies that would enable individuals to navigate unpredictable career trajectories. SDCM has been described as consisting of personal dispositions, readiness, or abilities/competences that can be developed to create employability and sustainable employment.

The conceptual model depicted below, acknowledges the influence of socioeconomic and other demographic variables (that include collectivistic elements) on students' international mobility aspirations and posit that career resources and career resilience may serve a moderating or mediating role. Barriers and enablers have also been included in the model below to assess how students interpret these factors to hinder or enable their decision-making processes that ultimately result in undertaking an international student mobility opportunity.

Career adaptability, employability, proactivity and resilience competencies have been emphasised as skills that will aid individuals to traverse increasingly complex career-life transitions and traumas. The conceptual

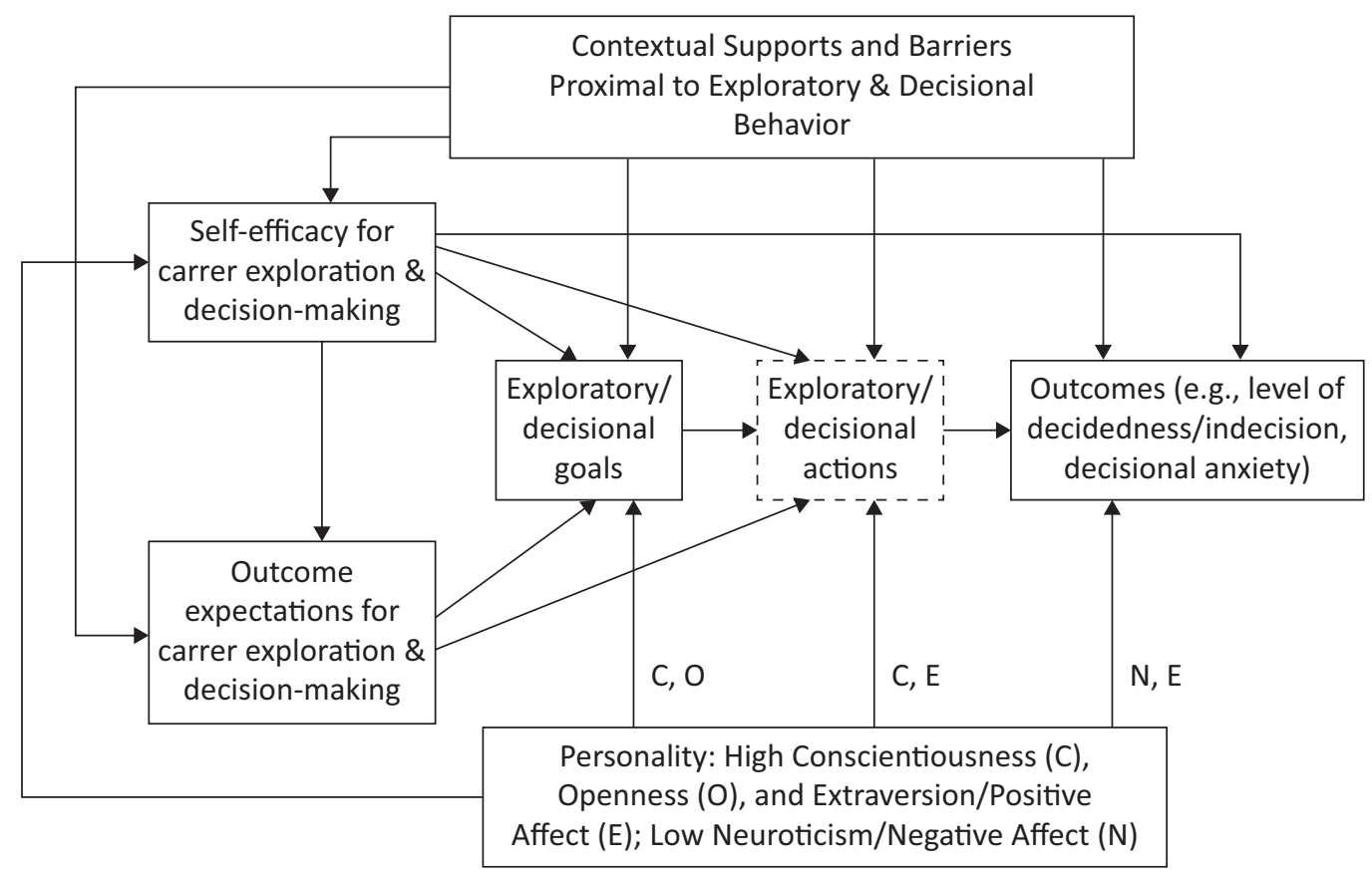

Figure 1. Model of career self-management adapted from Ireland and Lent (2018, p. 38). Reprinted with permission. 
model proposed here depicts the influence of socioeconomic and demographic factors on international student mobility aspirations as seen in Figure 2. Therefore, based on the conceptual model, career resources and career resilience are believed to function as moderators or mediators between mobility aspirations, motivations, and international student mobility in students. However, this model will be empirically tested in a followup study to assess the applicability to South African student groups in particular, and then findings will be critically discussed if they can be transferred to international student population groups in general. Thereby, the literature base of international student mobility research is extended with the inclusion of a conceptual model that is based on organizational psychology theoretical underpinnings.

\section{Conclusions and Future Research}

This article provides a systematic review of the corpus of literature available on international student mobility barriers, enablers, and determinants. In the second step we extended the findings to a South African university student group, due to limited of research studies on international student mobility in a Global South context. And lastly, we presented a theoretical integration and presented a conceptual model that could be used to predict future mobility motivations and aspirations not only in South African University students but other international student groups. This model will be tested in a future follow-up study where two student groups will be assessed (mobile versus non-mobile) to measure the differences that emerge and to what extent they mirror those that were documented in the international student mobility studies presented here, as well as other relevant international student mobility findings that may be outside the scope of this study. Once we have understood the interplay of all the factors discussed here, interventions can be created to support international mobility decision-making amongst students who qualify for international scholarships that would cover the costs of their international mobility experience, whether it is a short-exchange opportunity, an online hybrid international programme or a relevant training programme. This would facilitate the transference of international skills to make graduate students globally competitive, something that is particularly relevant in the transition to sustainable employability, supporting the demand and economic integration of professionals who will be able to adapt to a continuously changing world of work and enable sustainable employment. We believe that the conceptual framework and model we have created has a priori wide applicability to all international students because the model includes variables that have not yet been examined together in describing student mobility decision-making processes.

In conclusion, we believe that the theoretical integration and conceptual model presented here could be used to predict future mobility motivations and aspirations of international students worldwide by identifying the influences of socioeconomic factors, career orientations, barriers and enablers involved in this decisionmaking process.

\section{Acknowledgments}

We would like to give special recognition to Dr. Didier Ruedin from the University of Neuchâtel and the Swiss

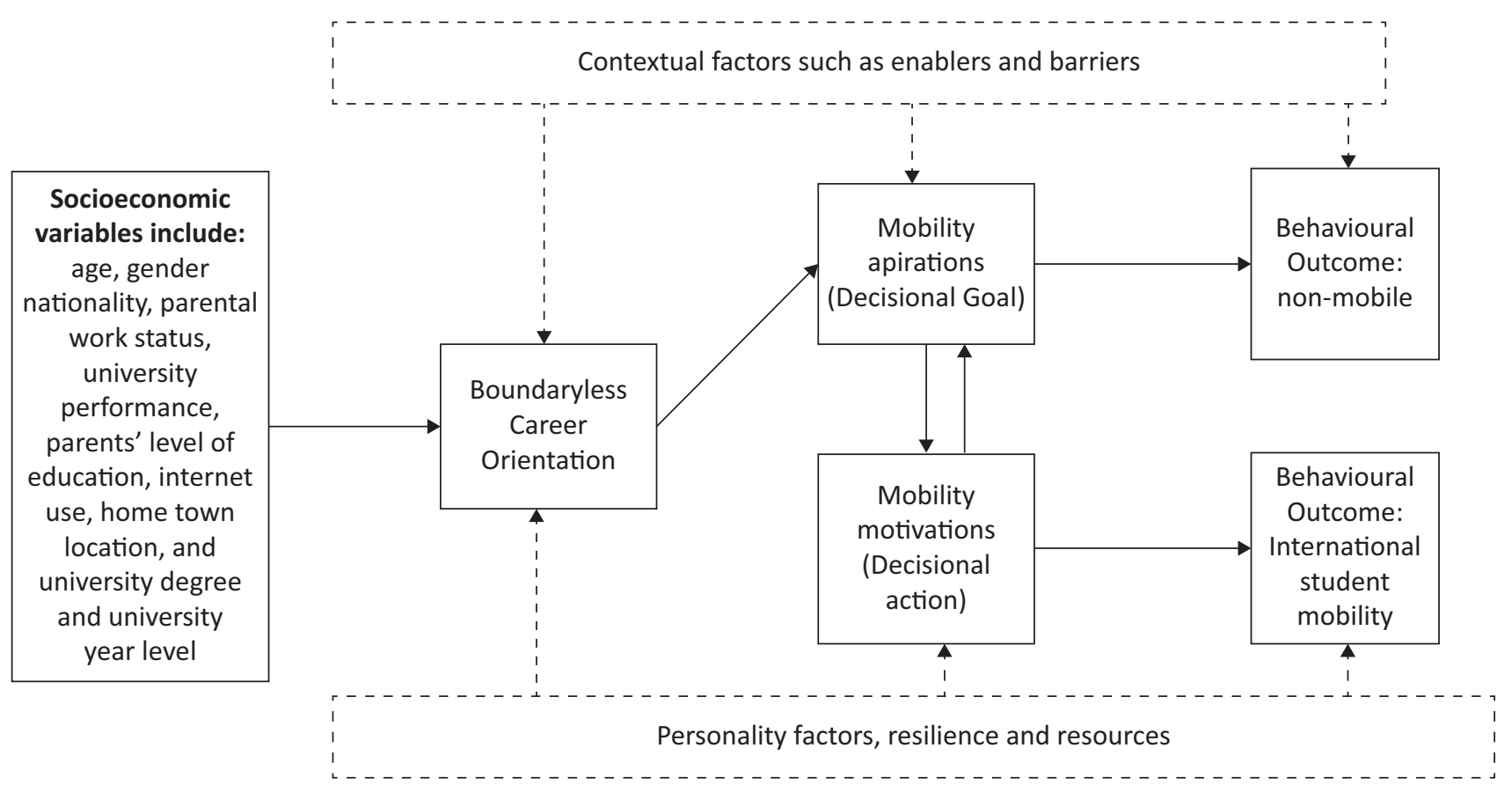

Figure 2. Boundaryless career conceptual model of international student mobility decision-making. 
Forum for Population and Migration Studies (SFM) Grant as part of the Swiss-Sub Saharan African Migrant Network (SSAM) Project. We also thank the University of Bern and Stellenbosch University for collaborating with the authors in this research project.

\section{Conflict of Interests}

The authors declare no conflict of interests.

\section{Supplementary Material}

Supplementary material for this article is available online in the format provided by the author (unedited).

\section{References}

Albien, A. J. (2019). In search of addressing people's career adaptability and career identity needs: Constructing the Shaping Career Voices Intervention. In J. G. Maree (Ed.), Handbook of innovative career counselling (pp. 269-288). New York, NY: Springer.

Beine, M., Noël, R., \& Ragot, L. (2013). The determinants of international mobility of students (CESifo Working Paper No. 3848). Munich: Center for Economic Studies and ifo Institute (CESifo), University of Munich.

Blustein, D. L., Franklin, A. J., Makiwane, M., \& Gutowski, E. (2017). Indigenisation of career psychology in South Africa. In G. B. Stead \& M. B. Watson (Eds.), Career psychology in the South African context (3rd ed., pp. 196-209). Pretoria: Van Schaik Publishers.

Cao, L., Hirschi, A., \& Deller, J. (2012). Self-initiated expatriates and their career success. Journal of Management Development, 31(2), 159-172. https://doi.org/ 10.1108/02621711211199494

Cosser, M. (2018). Differential pathways of South African students through higher education. International Journal of Educational Development, 59, 100-109.

De Haas, H. (2010). The internal dynamics of migration processes: A theoretical inquiry. Journal of Ethnic and Migration Studies, 36(10), 1587-1617.

Efiritha, C., Nogget, M., \& Nyevero, M. (2012). Voices of conflict: Students' and lecturers' perceptions of the utility of the bridging program at university. US-China Education A, 4, 452-446. Retrieved from https://eric.ed.gov/?id=ED533547

Findlay, A., King, R., Findlay, A. M., Ahrens, J., \& Dunne, M. (2012). World class? An investigation of globalisation, difference and international student mobility. Transactions of the Institute of British Geographers, 37, 118-131.

Gesing, P., \& Glass, C. (2018). First generation international students and the 4Ds shaping the future of global student mobility: A comparative report analysis. Journal of Comparative \& International Higher Education, 10, 24-27.

Hou, C., \& Du, D. (2020). The changing patterns of international student mobility: A network per- spective. Journal of Ethnic and Migration Studies. Advance online publication. https://doi.org/ 10.1080/1369183X.2020.1797476

Institute of International Education. (2011). Open Doors 2011 report on international educational exchange: Annual census of international students. New York, NY: IIE. Retrieved from https://visaservices.duke. edu/sites/default/files/Student_OpenDoors20132014_CountryOfOrigin.pdf

Ireland, G. W., \& Lent, R. W. (2018). Career exploration and decision-making learning experiences: A test of the career self-management model. Journal of Vocational Behavior, 106, 37-47.

King, R., Findlay, A., \& Ahrens, J. (2010). International student mobility literature review. Bristol: HEFCE.

Kritz, M. M., Lim, L. L., \& Zlotnik, H. (1992). International migration systems: A global approach. Oxford: Oxford University Press.

Lent, R. W., \& Brown, S. D. (2013). Social cognitive model of career self-management: Toward a unifying view of adaptive career behavior across the life span. Journal of Counseling Psychology, 60(4), 557-568.

Lent, R. W., Ezeofor, I., Morrison, M. A., Penn, L. T., \& Ireland, G. W. (2016). Applying the social cognitive model of career self-management to career exploration and decision-making. Journal of Vocational Behavior, 93, 47-57.

Li, W., Lo, L., Lu, Y., Tan, Y., \& Lu, Z. (2020). Intellectual migration: Considering China. Journal of Ethnic and Migration Studies. Advance online publication. https://doi.org/10.1080/1369183X.2020.1739393

Mataure, M. (2013). Citizens perception on migration in South Africa (Afrobarometer Briefing Paper No. 112). Accra: Afrobarometer. Retrieved from https://media. africaportal.org/documents/afrobriefno112_2.pdf

O’Flaherty, M., Skrbis, Z., \& Tranter, B. (2007). Home visits: Transnationalism among Australian migrants. Ethnic and racial studies, 30(5), 817-844.

Potgieter, M., Harding, A., Kritzinger, Q., Somo, C., \& Engelbrecht, J. (2015). Reflections of science students on their experiences of an academic development programme in South Africa: Part 1. South African Journal of Higher Education, 29(1), 108-131.

Prazeres, L. (2013). International and intra-national student mobility: Trends, motivations and identity. Geography Compass, 7, 804-820.

Ravasi, C., Salamin, X., \& Davoine, E. (2015). Crosscultural adjustment of skilled migrants in a multicultural and multilingual environment: An explorative study of foreign employees and their spouses in the Swiss context. The International Journal of Human Resource Management, 26(10), 1335-1359.

Skrbis, Z., Woodward, I., \& Bean, C. (2014). Seeds of cosmopolitan future? Young people and their aspirations for future mobility. Journal of Youth Studies, 17(5), 614-625.

Souto-Otero, M., Huisman, J., De Beerkens, M., Wit, H., \& Vujic, S. (2013). Barriers to international student 
mobility: Evidence from the Erasmus program. Educational Researcher, 42(2), 70-77.

Statistics South Africa. (2019). Mid-year population estimates: 2019. Pretoria: Statistics South Africa.

Sullivan, S. E., \& Arthur, M. B. (2006). The evolution of the boundaryless career concept: Examining physical and psychological mobility. Journal of Vocational Behavior, 69(1), 19-29.

The World Bank. (2015). Data: GINI index (World Bank estimate). The World Bank. Retrieved from http:// data.worldbank.org/indicator/SI.POV.GINI

Verbik, L., \& Lasanowski, V. (2007). International student mobility: Patterns and trends. World Education News and Reviews, 20(10), 1-16.

Wickramasinghe, A. A. I. N., \& Wimalaratana, W. (2016). International migration and migration theories. Social Affairs, 1(5), 13-32.

Yakhina, Z. S., Yakovlev, S. A., Kozhevnikova, N. V., Nuretdinova, Y. V., \& Solovyeva, N. A. (2016). Practical recommendations for university graduates' readiness formation to occupational mobility. International Journal of Environmental and Science Education, 11(15), 7358-7367.

\section{About the Authors}
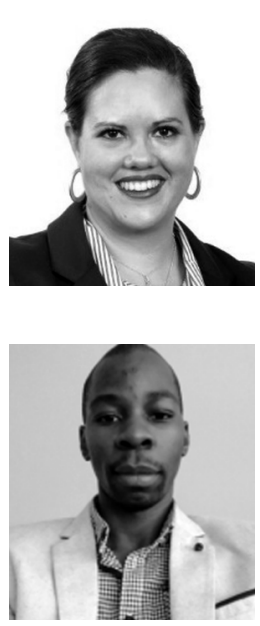

Anouk J. Albien (PhD) is a Post-Doctoral Researcher previously based at the Psychology Institute of Bern University. She completed her PhD at the Stellenbosch University Psychology Department and worked as a research assistant in the Strategy and Internationalization Vice Rector's Office. She has expertise in both quantitative and qualitative research and aims to contribute to advancing the career-life course development of adolescents, youth, and adults to create new career-life narratives during their career transition (i.e., migration and or international mobility) using both etic and/or emic research approaches.

Ngoako J. Mashatola is a Mcom Industrial psychology graduate (Stellenbosch University). He is registered with the Health Professions Council of South Africa (supervised independent practice) and completed his internship at the Military Psychological Institute of Pretoria. He is currently serving in the South African National Defence Force as a Lieutenant. His research interests include industrial psychology, research methodology, career psychology, organisational behaviour, and statistical modelling. He is keen on conducting research focusing on career psychology and psychological assessments in terms of talent analytics to help organisations achieve person-job/organisation fit. 